\title{
Stock Return and Trading Volume - An Application of the Markov Switching Model
}

\author{
Jing-Tung $\mathrm{Wu}^{1}$ \\ ${ }^{1}$ Department of Finance, Ming Chuan University, Taiwan \\ Correspondence: Jing-Tung Wu, Department of Finance, Ming Chuan University, Chung Shan N. Road, Taipei, \\ Taiwan. E-mail: jtwu@mail.mcu.edu.tw
}

Received: January 20, 2016

Accepted: January 25, $2016 \quad$ Online Published: February 29, 2016

doi:10.20849/abr.v1i1.27

URL: http://dx.doi.org/10.20849/abr.v1i1.27

\begin{abstract}
The relationship between stock return and trading volume has been extensively documented by earlier studies. Financial academics unveiled some potential reasons of this phenomenon, but it still left for several inconclusive evidences. This paper employs the Markov switching model (MSM) to investigate the relationship. The results identify that second regime exist and persist, which is consistent with earlier study indicating that there are complex influences in stock return and trading volume. One possible explanation would be that people are not always rational; their financial decisions are influenced by behavioral biases. If people change their beliefs or preferences, then the regime switches. This leads to the conclusion that, the results are strongly in favor of a non-linear relation between stock return and trading volume. Also, it is interesting to find that industry play an important role. The deviations of the regime parameters are different across industries, which stands for risk-varying and is fit to the conventional wisdoms. This paper further tests the glamour (value) stock effect by the MSM; the result shows that the factor does affect the probabilities of the expected regime duration periods.
\end{abstract}

Keywords: industry, Markov switching model, risk-varying, stock return, trading volume

\section{Introduction}

An old Wall Street proverb said that it takes trading volume to make price moving. Trading volume is relatively high in bull markets and low in bear markets. On the contrary, Fama $(1976,1991)$ proposed that if the market is efficient the trading volume should not have any predictive power of the return (efficient market hypothesis: EMH). If the market is inefficient, stock price is not immediately and correctly adjust to information, such that the market statistics may content information that is not yet incorporated into the price. Trading volume is one of the market statistics. Early literatures have found evidences that supported the EMH. But in recently many anomalies against the EMH were exposed.

Why investors trade securities? Basic financial theory argues that they buy or sell according to expectations regarding the future prices of assets. Shifts in the demand for stock may be due to the information about the macroeconomics environment, industry and firm. The weak-form EMH claims that stock prices reflect all information that can be derived by examining the history of past prices and trading volume. If the data conveys valuable signals about future price patterns, the signals will lose their value as they become widely known.

However, Epps (1975), Copeland (1976), Jennings, Starks, and Fellingham (1981) found a positive correlation between stock price change and trading volume. The model of Copeland and Jennings et al. relies on the heterogeneity belief across investors, which is difference with the classical financial theory. It also prohibits uninformed investors to learn from the informed traders. They separated the investors into several different groups. Each group has their own vision for the future. Campbell, Grossman, and Wang (1993) said that prices fall could be due to public information that has caused all investors to reduce their valuation of the stock. Their model also implies that a price decline on a high volume day is more likely than a stock price decline on a low volume day. Furthermore, Conrad, Hameed, and Niden (1994) used a contrarian portfolio strategy to test the relationship between stock return and trading volume, their finding is strongly consistent with Copeland (1976) and Campbell et al. (1993). In addition, Blume, Easley, and O'Hara (1994) showed that trading volume provides information about the quality of trader's information. Stock returns and trading volume are jointly determined by market situation. They also found that, traders who use the more 
information from price and trading volume will do better than traders who do not. The information on trading activity appears to be an important predictor of stock return.

Basic financial theory suggests that information is important for return and trading volume determination. But it lacks of discussion about how the information be incorporated into them. Behavioral finance offers more clear explanations. It treats the human being (investors) as the leading role of the financial decision. Shefrin and Statman (1985) suggested that the main determinant of trading volume is investor representativeness. Odean (1998) argued similar hypothesis that investor overconfidence is the key determinant of trading volume. People are different in the way of they form judgments. Some rely on heuristics, while the others use Bayes' rule. Even among those who rely on heuristics, the degree of heterogeneity could be widely. Barberis, Shleifer, and Vishny (1998) used behavioral model to explain the short term price momentum and long term price reversals. They assumed that investors' sentiment is a regime-switching process. Sometimes the market are underreacted, sometimes are overreacted. News is incorporated slowly into prices. Behavioral finance describes a more complicated world to deal with the information. Follow their observations that the MSM could be a suitable model to capture the phenomenon.

Lee and Swaminathan (2000) provided a theory of momentum life cycle (MLC) to explain the complex relationship between stock price patterns and trading volume in the US stock market during 1965 to 1995 . At the cycles of investor favoritism to neglect, stocks go through the overvalued to the undervalued periods. If the stock prices are high and overvalued, it eventually will revert. When the stock prices are relatively low and undervalued, in the next stage, they will become low-volume winners. The cycle then repeats itself. But they noted that the turnings points between stages may be random and are difficult to pinpoint. They found that firms with high turnover ratios exhibit many glamour characteristics, earn lower futures returns; that firms with low turnover ratios exhibit many value characteristics, earn higher futures returns, and have consistently more earnings surprises over the next eight quarters. Stock returns and trading volume are jointly determined by the market dynamics. The MLC provided an integrated explanation about the relationship between stock returns and trading volume. The proposition of the MLC is very similar to the MSM.

In recent years, the researches of trading volume are extensive. It gives rise to the interest to the cross-countries test of the theory. For example, Ding, Melnish, and Wongchoti (2008) investigated the short-horizon returns and trading volume among seven Asia-Pacific markets. Their results showed that country-varying relationship between return and volume. In general, they observed a monotonic relationship between contrarian/momentum profits and trading volume. However, the results are not fully consistent across countries. Especially, Taiwan seems to desire the most unclear conclusions. For example, it is not consistent with the propositions of Daniel, Hirshleifer, and Subrahmanyam (1998), Lee and Swaminathan (2000). And the relationship between returns and trading volume is inconclusive with Hong and Stein (1999). What is the reason make the difference cross countries are left for further research.

Many financial market traders believe that past price and volume data provide indicators for future price movement, and use the information contains in volume. Then the "specific volume statistic" enters trader's beliefs. But previous studies do not provide a general rule about the relationship. The mechanism that adds the "specific volume statistic" into price change is still unclear. Like Lee and Swaminathan (2000) said: the turnings points between different stages may be random and hard to pinpoint. Follow Barberis et al. (1998) assumption, the investor's sentiment is a regime-switching process. When will the investor's sentimental change is not easy to recognize.

Hence, this paper employs the MSM which could separate the investors' sentiment regime, and tries to find out the probability of regime change. Based on weekly returns of stocks in TWSE during January 2000 to June 2015, this paper finds that there is always a second regime that is difficult to explain theoretically. Another interest finding is the industry factor plays an important role of the estimation process. Parameters of the MSM vary across industries, it is fitted to the conventional wisdom that some industries are more stable and some are more volatile. The glamour (value) stock effect has also evaluated by the MSM. The remainder of the paper is structured in the following manner. In the next section, this paper introduces the Markov model and provides the testing equation. This might be an important step to figure out the role that trading volume play. Section 3 presents the empirical analysis. Finally, Section 4 concludes this paper and left something for further research.

\section{Markov Switching Model (MSM)}

The MSM is a popular time-varying volatility model, which allows researchers to identify separate joint 
normal distributions for the stock returns. The MSM was popularized by Hamilton's (1989) study of business cycle dynamics. In recent years, researchers have extensively used the MSM to predict price movements and try to capture volatility dynamics.

The regime generating process is assumed as a Markov chain with finite regimes $S_{t}$. In a two regimes case, if $s_{t}=1$, then the process is in regime one, while $s_{t}=2$ means that the process is in regime two. It is always assumed that $s_{t}$ cannot be observed directly, but only infer its operation through the observed behavior of $y_{t}$. The parameters could fully describe the probability governing $y_{t}$ are the two regime transition probabilities, $p_{11}$ and $p_{22}$. The transition of regimes is stochastic, one is never sure whether there will be a switch of regime or not. The probabilities transition matrix $\mathrm{P}$ controls the probability of a switch from regime one to regime two, or from regime two to regime one. The probabilities transition matrix is usually assumed constant. The MSM assumes that the probability of a change in regime depends on the most recent regime. The probabilities transition matrix $\mathrm{P}$, defined as follows,

$$
\begin{aligned}
& P=\left(\begin{array}{l}
\operatorname{Pr}\left(s_{t}=1 \mid s_{t-1}=1\right)=p_{11}, \operatorname{Pr}\left(s_{t}=1 \mid s_{t-1}=2\right)=p_{21} \\
\operatorname{Pr}\left(s_{t}=2 \mid s_{t-1}=1\right)=p_{12}, \operatorname{Pr}\left(s_{t}=2 \mid s_{t-1}=2\right)=p_{22}
\end{array}\right) \\
& =\left(\begin{array}{ll}
1-p_{12}, p_{21} \\
p_{12} & , 1-p_{21}
\end{array}\right)
\end{aligned}
$$

The data $y_{t}$ is summarized by six population parameters,

$$
\theta=\left(\mu_{1}, \mu_{2}, \sigma_{1}, \sigma_{2}, p_{11}, p_{22}\right)
$$

The estimation procedure uses Gaussian maximum likelihood method, and the optimal model is selected by minimum Akaike information criteria (AIC). If the Markov chain is presumed to be ergodic, one can use the unconditional probabilities. Engle and Hamilton (1990) have investigated the change in exchange rates and found that MSM is a good approximation to the underlying processes, and have excellent predictive power of nonlinearities time series. See Hamilton (1994) for further details.

Trading volume contents information has long been a subject of empirical studies. The traders use some special volume statistics to update their beliefs (Blume et al., 1994). For analyzing the relationship between stock returns and trading volume, the relationship is given by the following equation:

$$
R_{t}=\alpha_{s_{t}}+\beta_{s_{t}} T V_{t}+\varepsilon_{t}, \varepsilon_{t} \sim N\left(0, \sigma_{s_{t}}^{2}\right)
$$

where $R_{t}$ denotes the stock returns at time t, $T V_{t}$ denotes the trading volume at time t. The coefficients $\alpha_{s_{t}}$ and $\beta_{s_{t}}$ depend on the regime variable $s_{t}$, which may take the values of one or two. Lee and Swaminathan (2000) found that the cycles of MLC repeated, but the turning points between phases are hard to pinpoint. This paper adopts the MSM, and tries to figure out the probability of regimes change by the estimation procedure. The MSM provides an opportunity to find out the turning points.

Another factor used by previous studies is the ratio of market value to book value (MB). Lee and Swaminathan (2000) and many researchers used this factor on behalf of stock characteristic factor. They titled higher (lower) MB ratio stock as glamour (value) stocks. In the MLC, glamour stocks and value stocks play a very different scenario. This paper adds the ratio to the evaluation equation, and tries to unveil its affection. Such that equation 
(3) will be altered to the following equation:

$$
R_{t}=\alpha_{s_{t}}+\beta_{s_{t}} T V_{t}+\gamma_{s_{t}} M B_{t}+\varepsilon_{t}, \varepsilon_{t} \sim N\left(0, \sigma_{s_{t}}^{2}\right)
$$

The coefficients $\alpha_{s_{t}}, \beta_{s_{t}}$ and $\gamma_{s_{t}}$ depend on the regime variable $s_{t}$, which may take the values one or two.

The motivation to study the effect of trading volume comes from the fact that conventional models do not fully explain stock returns. The MSM uses the probabilities transition matrix to control the probability of a switch from different regime. It is not necessary to rely on unknown variables, thus the selection of those explanation variables would not be a problem for the MSM. The benefit makes the MSM easier to apply to the empirical studies.

\section{Empirical results}

\subsection{The Statistics of Data}

The weekly TWSE data are taken from the Taiwan Economic Journal (TEJ), with the sample period covering January 2000 through June 2015. Every industry index and stock return is calculated as the percentage change with last week. The turnover is used as the proxy of trading volume, which is the transaction volume divided by total shares outstanding. This method was widely used by previous studies, such as Gervais, Kaniel, and Mingelgrin (2001) and Gurgul and Syrek (2013). Many authors use the illiquidity measure developed by Amihud (2002). But Lou and Shu (2014) claim that it is lack of theoretical support. The estimation process is performed using MATLAB. Fig. 1 presents the plot of market return and trading volume (turnover).

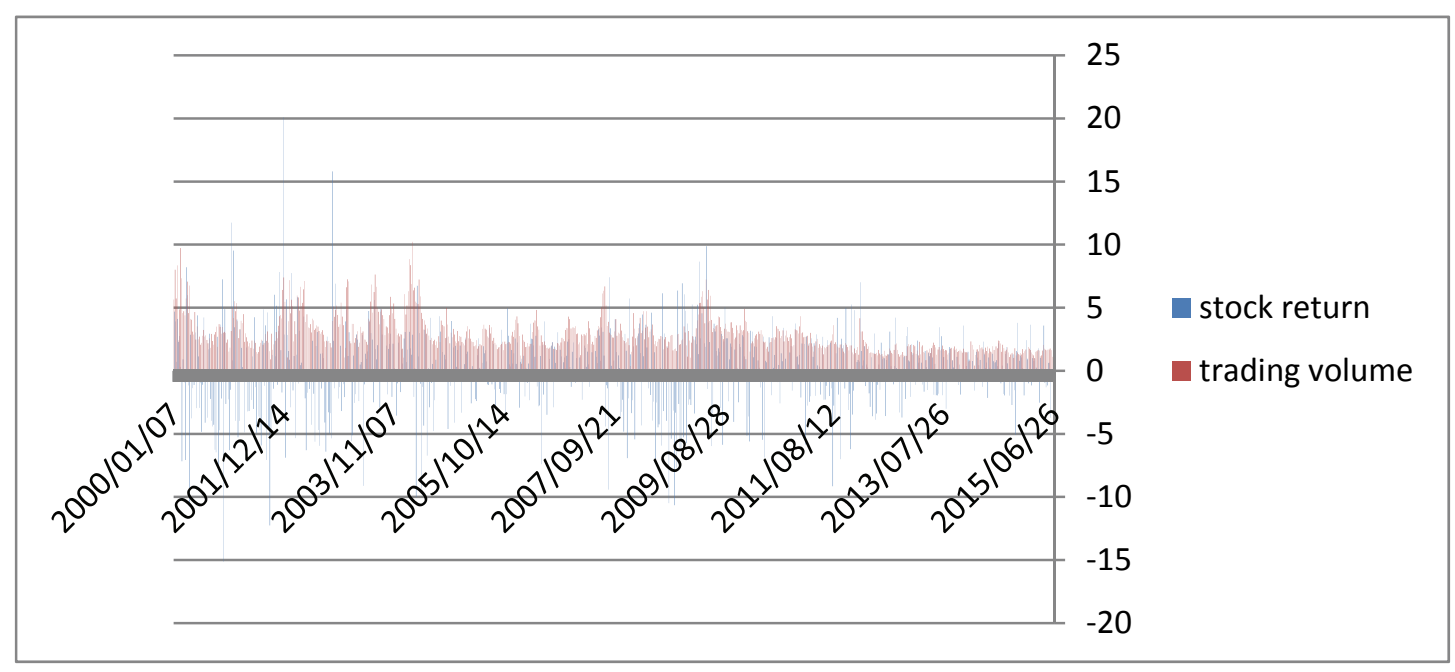

Figure 1. Stock return and trading volume of the market

This paper carries out the Augmented Dickery-Fuller (ADF) and Phillips-Perron (PP) unit root tests for whether the series is stationary. The results show that stock return and trading volume are stationary. This paper also performs two and four weeks lagged for the Granger causality test. It is found that the Granger causality between stock return and trading volume is not significant. We could treat the trading volume as an exogenous variable.

Since these tests are well known and have been widely used in researches, the mathematical details are not presented here. This paper also omits the details of the results for the simplification purpose. The details of these testing results are available upon request from the author.

\subsection{Regression Model: Industry Index Return and Trading Volume}

For comparisons with the MSM, table 1 presents the results of regression model to evaluate the relationship between return and trading volume. The $R^{2}$ between the market return and trading volume is $4.52 \%$. Automobile, building material \& construction and paper \& pulp industries earn the higher relationship, which are $9.85 \%, 9.13 \%$ and $9.04 \%$ respectively. The lower are chemical, glass \& ceramics and plastic industries, which 
are $3.46 \%, 2.73 \%$ and $1.67 \%$.

The results show that the relationship between stock returns and trading volume is not a one-one function. Automobile industry earns the highest $R^{2}$ among the industries; however it is only $9.85 \%$. Not to mention the plastic industry $R^{2}$, it is merely $1.67 \%$. This is a scenario not covered by the regression model, and gives rise to apply a more appropriate model for capturing the relationship between return and trading volume.

Table 1. The statistics of return and trading volume

\begin{tabular}{|c|c|c|c|c|c|c|c|c|c|}
\hline \multirow[t]{2}{*}{ Industry } & \multicolumn{4}{|c|}{ Return } & \multicolumn{4}{|c|}{ Trading volume } & \multirow[b]{2}{*}{$R^{2}$} \\
\hline & $\max$ & mean & $\min$ & $\sigma_{r}$ & $\max$ & mean & $\min$ & $\sigma_{t v}$ & \\
\hline Cement & 16.27 & 3.68 & -21.31 & 4.99 & 14.04 & 2.21 & 0.25 & 1.83 & 4.71 \\
\hline Food & 16.63 & 2.87 & -23.62 & 4.00 & 11.48 & 1.35 & 0.29 & 1.75 & 3.93 \\
\hline Plastics & 17.84 & 2.81 & -17.38 & 3.93 & 12.43 & 1.17 & 0.18 & 1.68 & 1.67 \\
\hline Textiles & 14.03 & 3.29 & -15.92 & 4.38 & 11.71 & 1.26 & 0.23 & 1.74 & 4.76 \\
\hline $\begin{array}{l}\text { Electric } \\
\text { Machinery }\end{array}$ & 13.68 & 2.53 & -12.98 & 3.44 & 15.62 & 1.38 & 0.32 & 192 & 5.38 \\
\hline Electrical \& cable & 18.59 & 3.69 & -18.18 & 4.95 & 23.80 & 1.84 & 0.33 & 2.73 & 6.03 \\
\hline Chemical & 13.46 & 2.79 & -15.78 & 3.79 & 15.90 & 1.81 & 0.39 & 2.40 & 3.46 \\
\hline Glass, Ceramics & 16.68 & 3.42 & -18.74 & 4.65 & 15.50 & 1.41 & 0.10 & 1.92 & 2.73 \\
\hline Paper, Pulp & 19.43 & 3.39 & -15.43 & 4.60 & 26.42 & 2.06 & 0.13 & 2.99 & 9.04 \\
\hline Iron \& Steel & 12.88 & 2.59 & -14.73 & 3.55 & 19.99 & 2.03 & 0.15 & 2.81 & 5.33 \\
\hline Rubber & 17.83 & 3.30 & -19.21 & 4.52 & 19.38 & 2.09 & 0.46 & 2.82 & 6.16 \\
\hline Automobile & 23.12 & 3.25 & -17.40 & 4.44 & 11.90 & 1.70 & 0.15 & 2.26 & 9.85 \\
\hline Electron & 21.55 & 2.96 & -15.97 & 4.00 & 17.60 & 1.64 & 0.49 & 2.33 & 5.48 \\
\hline $\begin{array}{l}\text { Building } \\
\text { Material \& } \\
\text { Construction }\end{array}$ & 24.68 & 4.12 & -23.76 & 5.61 & 21.55 & 2.49 & 0.43 & 3.36 & 9.13 \\
\hline $\begin{array}{l}\text { Shipping \& } \\
\text { Transportation }\end{array}$ & 22.30 & 3.41 & -21.33 & 4.62 & 12.62 & 1.42 & 0.30 & 1.85 & 5.33 \\
\hline Tourism & 20.26 & 3.32 & -22.02 & 4.80 & 21.93 & 2.12 & 0.23 & 2.99 & 8.90 \\
\hline $\begin{array}{l}\text { Finance \& } \\
\text { Insurance }\end{array}$ & 22.31 & 3.02 & -18.03 & 4.19 & 10.72 & 0.91 & 0.17 & 1.29 & 8.20 \\
\hline $\begin{array}{l}\text { Trading \& } \\
\text { Consumer's } \\
\text { Goods Industry }\end{array}$ & 12.84 & 2.66 & -13.54 & 3.58 & 11.55 & 1.30 & 0.19 & 1.75 & 3.84 \\
\hline Market index & 20.10 & 2.57 & -15.13 & 3.47 & 11.61 & 1.09 & 0.66 & 1.48 & 4.52 \\
\hline
\end{tabular}

Note: The $\sigma_{r}$ stands for the standard deviation of return; $\sigma_{t v}$ stands for the standard deviation of trading volume. This paper has tested the relationship between return and trading volume with one week lag, the $R^{2}$ is much lower than this table presents.

\subsection{MSM: Industry Index Return and Trading Volume}

This sub-section uses the MSM to evaluate the relationship between industry index return and trading volume. The MSM allows trading volume switching between two regimes, one corresponding to a low volatility and the other to a high volatility period. The estimation procedure uses the Gaussian maximum likelihood method, and 
the optimal model was selected by minimum Akaike information criteria (AIC). Table 2 presents the results. This paper illustrates only two regimes condition due the parameters of three regimes MSM are generally not significant.

Table 2. The MSM parameters of industry

\begin{tabular}{|c|c|c|c|c|c|c|c|}
\hline Industry & $\mu_{1}$ & $\mu_{2}$ & $\sigma_{1}$ & $\sigma_{2}$ & $\sigma_{r}$ & $p_{11}$ & $p_{22}$ \\
\hline Cement & $0.86^{* * *}$ & -0.63 & $4.32^{* * *}$ & $5.29^{* * *}$ & 4.99 & $0.90^{* *}$ & $0.89^{* * *}$ \\
\hline Food & $0.53^{* * *}$ & $0.50^{*}$ & $2.95^{* * *}$ & $6.40^{* * *}$ & 4.00 & $0.99^{* * *}$ & $0.94^{* * *}$ \\
\hline Plastics & $0.49^{* *}$ & -0.17 & 3.40 & $4.17^{* * *}$ & 3.93 & 0.90 & 0.89 \\
\hline Textiles & $0.60^{* * *}$ & $0.53^{* * *}$ & $2.65^{* * *}$ & $5.82^{* * *}$ & 4.38 & 0.82 & 0.72 \\
\hline Electric Machinery & $0.70^{* * *}$ & -0.76 & 2.91 & 3.68 & 3.44 & 0.91 & 0.84 \\
\hline Electrical \& Cable & $0.47^{* * *}$ & $0.45^{* * *}$ & $2.86^{* * *}$ & $6.56^{* * *}$ & 4.95 & $0.91^{* * *}$ & $0.87^{* * *}$ \\
\hline Chemical & $0.37^{* * *}$ & 0.30 & $2.44^{* * *}$ & $5.75^{* * *}$ & 3.79 & 0.82 & 0.33 \\
\hline Glass, Ceramics & $0.43^{* * *}$ & $0.42^{* * *}$ & $2.53^{* * *}$ & $5.70^{* * *}$ & 4.65 & $0.90^{* * *}$ & $0.92^{* * *}$ \\
\hline Paper, Pulp & $0.71^{* * *}$ & -0.46 & $3.99^{* * *}$ & $4.88^{* * *}$ & 4.60 & $0.90^{* * *}$ & $0.90^{* * *}$ \\
\hline Iron \& Steel & $0.42^{* * *}$ & $0.22^{* *}$ & $2.01^{* * *}$ & $4.66^{* * *}$ & 3.55 & $0.90^{* * *}$ & $0.86^{* * *}$ \\
\hline Rubber & $0.41^{* * *}$ & $-0.78^{* *}$ & $3.79^{* * *}$ & $2.72^{* * *}$ & 4.52 & $0.96^{* * *}$ & 0.00 \\
\hline Automobile & $0.81^{* * *}$ & $-0.62^{* *}$ & 3.84 & 4.71 & 4.44 & $0.90^{* * *}$ & $0.90^{* * *}$ \\
\hline Electron & $0.39^{* * *}$ & $0.62^{* * *}$ & $2.47^{* * *}$ & $5.24^{* * *}$ & 4.00 & $0.96^{* * *}$ & $0.88^{* * *}$ \\
\hline Building Material \& Construction & $0.56^{* * *}$ & $0.51^{* * *}$ & $7.44^{* * *}$ & $3.08^{* * *}$ & 5.61 & $0.85^{* * *}$ & $0.90^{* * *}$ \\
\hline Shipping \& Transportation & $0.87^{* * *}$ & 0.08 & $3.95^{* * *}$ & $4.93^{* * *}$ & 4.62 & $0.91^{* * *}$ & $0.78^{* * *}$ \\
\hline Tourism & $0.96^{* * *}$ & -0.15 & $4.15^{* *}$ & $5.10^{* * *}$ & 4.80 & $0.90^{* * *}$ & $0.89^{* * *}$ \\
\hline Finance \& Insurance & $0.97^{* * *}$ & $1.11^{* * *}$ & $2.35^{* * *}$ & $5.70^{* * *}$ & 4.19 & $0.90^{* * *}$ & $0.82^{* * *}$ \\
\hline Trading \& consumer's Goods Industry & $0.57^{* * *}$ & $0.39^{*}$ & $2.61^{* * *}$ & $5.11^{* * *}$ & 3.58 & $0.99^{* * *}$ & $0.97^{* * *}$ \\
\hline Market index & $0.75^{* * *}$ & $-0.63^{* *}$ & $2.96^{* * *}$ & $3.71^{* * *}$ & 3.47 & $0.91^{* * *}$ & $0.84^{* * *}$ \\
\hline
\end{tabular}

Note: The asterisks refer to the level of significance, ${ }^{*} 10 \%,{ }^{* *} 5 \%,{ }^{* * *} 1 \%$. Standard error is omitted for brevity.

The results show that, there are thirteen industries perform significant two regimes. It is more than two-thirds of the sample. The average $p_{11}$ of these twelve industries is $0.91, p_{22}$ is 0.90 . Expected duration of regime one is $1 /\left(1-p_{11}\right)=11$ weeks, regime two is $1 /\left(1-p_{22}\right)=10$ weeks, each regime is highly persist. The market index performs similar result. Expected duration of regime one is 11 weeks, regime two is 6 weeks. Regime one is obviously longer than regime two.

It is interesting to find that industry factor plays an important role. The deviations of the regime parameters are high across industries. Taking the industries with both significant regime probability ( $p_{11}$ and $p_{22}$ are significant) 
as an example, in regime one, building material \& construction industry earns the highest $\sigma_{1}$, follow by cement and tourism industry, the lowest is iron \& steel industry. In regime two, electric \& cable industry earn the highest $\sigma_{2}$, follow by food, glass \& ceramics and finance \& insurance industry, the lowest is building material \& construction industry. In different regimes, the same industry may behave dissimilarity. Building material \& construction industry has the highest $\sigma_{1}$ in regime one, but $\sigma_{2}$ is the lowest in regime two.

This paper carefully checks the change among $\sigma_{1}, \sigma_{2}$ and $\sigma_{r}$. The average ratio of $\sigma_{1} / \sigma_{r}$ is 0.76 , $\sigma_{r} / \sigma_{2}$ is 0.90 . These results imply that by using the MSM to separate the sample into two regimes, the returns volatilities are different in two regimes and bring sizable deviations between $\sigma_{1}$ against $\sigma_{r}$, and $\sigma_{r}$ against $\sigma_{2}$. If we use original data to measure the volatility of return, it may cause some error of measurement. Here is the benefit that the MSM brings about. The volatility of the market is relative stable than the industries.

These findings fit to the Barberis et al. (1998) perspective which assumed that investor's sentiment is a regime-switching process. Sometimes the market are underreacted, sometimes are overreacted. This paper incorporates the information of trading volume, and selects the optimal model by minimum AIC. Table 2 shows that two-thirds industries exhibit two regimes and the duration of regimes approach 10 to 11 weeks. No wonder Barberis et al. (1998), Lee and Swaminathan (2000), Ding et al. (2008) and other previous studies have found that trading volume contains information. The relationship between return and trading volume is not a simple and monotonic behavior.

\subsection{MSM: Sub-Industry Index Return and Trading Volume}

To further checking the relationship of return and trading volume in detail. This paper breaks the electron industry into eight sub-electron industries. There are semiconductor, computer \& peripheral equipment, optoelectronic, communication \& internet, electronic parts \& components, electronic product distribution, information service and other electronic industries. The reasons for selecting electron industry are because its heavy trading volumes and possession of considerable market capitalization. Table 3 shows the results.

Table 3 lists sub-electron industries and the electron industry index. Here are four sub-industries perform significant two regimes. It is half of the entire industry. The average $p_{11}$ of these twelve industries is 0.95 , $p_{22}$ is 0.93 . Expected duration of regime one is 20 weeks, regime two is 14 weeks. Each regime is highly persistent and almost all the sub-electron industries perform the similar result. The deviation of the expected duration of different sub-electron industries varies only slightly. Electron industry performs the similar results with the sub-electron industries. Expected duration of regime one is 25 weeks, regime two is 8 weeks. Regime one is obviously longer that regime two.

The volatilities are different among sub-electron industries. Taking industries with both significant regime probability ( $p_{11}$ and $p_{22}$ are significant) as example, in regime one, electronic parts \& components industry earns the highest $\sigma_{1}$; the lowest is communication $\&$ internet industry. In regime two, electronic product distribution industry has the highest $\sigma_{2}$; the lowest is communication $\&$ internet industry. The highest $\sigma_{1}$ is 3.43 , the lowest is 1.87 . The highest $\sigma_{2}$ is 6.06 , the lowest is 3.37 . Volatilities vary widely.

The results show that the sub-electron industries contain two regimes and the regimes are highly persistent. 
Variations of volatilities are large. These findings are similar as the sub-section 3.3.

Table 3. The MSM parameters of sub-electron industries

\begin{tabular}{|c|c|c|c|c|c|c|}
\hline Sub-Industry & $\mu_{1}$ & $\mu_{2}$ & $\sigma_{1}$ & $\sigma_{2}$ & $p_{11}$ & $p_{22}$ \\
\hline Semiconductor & 0.24 & $3.04^{* * *}$ & $3.14^{* * *}$ & $5.91^{* * *}$ & $0.99^{* * *}$ & 0.97 \\
\hline Computer \& Peripheral Equipment & $0.38^{*}$ & 9.20 & $3.63^{* * *}$ & $4.71^{* * *}$ & $1.00^{* * *}$ & 0.92 \\
\hline Optoelectronic & $0.66^{* * *}$ & -2.28 & $4.84^{* * *}$ & 5.36 & $0.99^{* * *}$ & 0.00 \\
\hline Communication\& Internet & 0.08 & 0.23 & $1.87^{* * *}$ & $3.37^{* * *}$ & $0.92^{* * *}$ & $0.95^{* * *}$ \\
\hline Electronic Parts \& Components & $0.54^{* * *}$ & 0.28 & $3.43^{* * *}$ & $4.85^{* * *}$ & $0.97^{* * *}$ & $0.89^{* * *}$ \\
\hline Electronic Product Distribution & $0.52^{* * *}$ & $0.59^{* *}$ & $2.96^{* * *}$ & $6.06^{* * *}$ & $1.00^{* * *}$ & $1.00^{* * *}$ \\
\hline Information Service & 0.08 & $0.13^{*}$ & $2.19^{* * *}$ & $4.22^{* * *}$ & 0.98 & $0.99^{* * *}$ \\
\hline Other Electronic & $1.13^{* * *}$ & $1.09^{* *}$ & $2.99^{* * *}$ & $5.81^{* * *}$ & $0.89^{* * *}$ & $0.89^{* * *}$ \\
\hline Electron & $0.39^{* * *}$ & $0.62^{* * *}$ & $2.47^{* * *}$ & $5.24^{* * *}$ & $0.96^{* * *}$ & $0.88^{* * *}$ \\
\hline
\end{tabular}

Note: The asterisks refer to the level of significance, ${ }^{*} 10 \%,{ }^{* *} 5 \%,{ }^{* * *} 1 \%$. Standard error is omitted for brevity.

\subsection{MSM: Glamour (Value) Stock Effect}

Table 4-1. Semiconductor stock

\begin{tabular}{|c|c|c|c|c|c|}
\hline & \multirow[t]{2}{*}{ Regression } & \multicolumn{2}{|c|}{ MSM-TV } & \multicolumn{2}{|c|}{ MSM-TV-MB } \\
\hline & & Regime1 & Regime2 & Regime1 & Regime2 \\
\hline \multirow[t]{2}{*}{ intercept } & -0.39 & $-1.72^{* * *}$ & $-1.64^{*}$ & -1.42 & -0.09 \\
\hline & $(0.60)$ & $(0.33)$ & $(0.91)$ & $(0.68)$ & $(1.23)$ \\
\hline \multirow[t]{2}{*}{ TV } & $0.29^{* * *}$ & $0.48^{* * *}$ & $0.18^{* *}$ & $0.49^{* * *}$ & $0.30^{* * *}$ \\
\hline & $(0.06)$ & $(0.08)$ & $(0.08)$ & $(0.08)$ & $(0.12)$ \\
\hline \multirow[t]{2}{*}{ MB } & $-2.51^{*}$ & & & -0.84 & -4.81 \\
\hline & $(1.30)$ & & & $(1.53)$ & $(3.29)$ \\
\hline variance & 61.35 & 17.26 & 120.08 & 18.18 & 127.99 \\
\hline Loglik & -2213.50 & \multicolumn{2}{|c|}{-2146.34} & \multicolumn{2}{|c|}{-2144.47} \\
\hline \multicolumn{2}{|l|}{$\mathrm{P}_{11}$} & $0.89^{* * *}$ & & $0.89^{* * *}$ & \\
\hline \multicolumn{2}{|l|}{$\mathrm{P}_{22}$} & & $0.84^{* * *}$ & & $0.82^{* * *}$ \\
\hline \multicolumn{6}{|c|}{ Expected duration of regime } \\
\hline \multicolumn{2}{|l|}{ Regime1 } & 8.74 & & 9.23 & \\
\hline \multicolumn{2}{|l|}{ Regime2 } & & 6.16 & & 5.64 \\
\hline
\end{tabular}

Lee and Swaminathan (2000) found that the firms with high turnover ratios exhibit many glamour characteristics, earn lower futures returns; that firms with low turnover ratios exhibit many value characteristics, earn higher futures returns, and have consistently more earnings surprises over the next eight quarters. Stock returns and trading volume are jointly determined by the market dynamics.

This paper employs the idea of Lee and Swaminathan (2000), Baker and Wurgler (2006) and Ding et al. (2008), 
adding the characteristic factor into the MSM. The ratio of market value to book value (MB) has been use on behalf of the characteristic factor.

Stocks are obtained from the electron industry, including all stocks which have listed from January 2000 to June 2015. The estimation process is performed in MATLAB. The total samples are 112 stocks. For brevity, this paper randomly presents 8 stocks and lists it by sub-electron industries order. Empirical results show in tables 4-1 4-8. The others are available upon request from the author.

Table 4-2. Computer \& peripheral equipment stock

\begin{tabular}{|c|c|c|c|c|c|}
\hline & \multirow[t]{2}{*}{ Regression } & \multicolumn{2}{|c|}{ MSM-TV } & \multicolumn{2}{|c|}{ MSM-TV-MB } \\
\hline & & Regime1 & Regime2 & Regime1 & Regime2 \\
\hline \multirow[t]{2}{*}{ intercept } & -0.24 & $-0.84^{* *}$ & 0.82 & -0.20 & 0.12 \\
\hline & $(0.56)$ & $(0.33)$ & $(0.75)$ & $(0.48)$ & (Inf) \\
\hline \multirow[t]{2}{*}{ TV } & $0.29^{* * *}$ & $0.54^{* * *}$ & $-0.06^{* *}$ & $0.57^{* * *}$ & 0.02 \\
\hline & $(0.04)$ & $(0.06)$ & $(0.11)$ & $(0.06)$ & (Inf) \\
\hline \multirow[t]{2}{*}{ MB } & -0.37 & & & -0.32 & 0.19 \\
\hline & $(0.28)$ & & & $(0.37)$ & (Inf) \\
\hline variance & 34.19 & 27.73 & 41.65 & 27.70 & 41.65 \\
\hline Loglik & -2055.92 & \multicolumn{2}{|c|}{-2033.46} & \multicolumn{2}{|c|}{-2032.05} \\
\hline $\mathrm{P}_{11}$ & & $0.90^{* * *}$ & & 0.90 & \\
\hline $\mathrm{P}_{22}$ & & & $0.88^{* * *}$ & & 0.87 \\
\hline \multicolumn{6}{|c|}{ Expected duration of regime } \\
\hline Regime1 & & 10.18 & & 10.34 & \\
\hline Regime2 & & & 8.64 & & 7.70 \\
\hline
\end{tabular}

Table 4-3. Optoelectronic stock

\begin{tabular}{|c|c|c|c|c|c|}
\hline & \multirow[t]{2}{*}{ Regression } & \multicolumn{2}{|c|}{ MSM-TV } & \multicolumn{2}{|c|}{ MSM-TV-MB } \\
\hline & & Regime1 & Regime2 & Regime1 & Regime2 \\
\hline \multirow[t]{2}{*}{ intercept } & $-1.62^{* * * *}$ & $-2.09^{* * *}$ & $-5.85^{*}$ & -0.70 & $-2.92^{* * *}$ \\
\hline & $(0.34)$ & $(0.27)$ & $(0.92)$ & $(0.54)$ & $(0.65)$ \\
\hline \multirow[t]{2}{*}{$\mathrm{TV}$} & $0.45^{* * *}$ & 0.58 & $0.70^{* * *}$ & $0.38^{* * *}$ & $0.52^{* * *}$ \\
\hline & $(0.05)$ & (Inf) & $(0.08)$ & $(0.10)$ & $(0.07)$ \\
\hline \multirow[t]{2}{*}{ MB } & $-0.73^{* *}$ & & & -0.63 & $-0.72^{* * *}$ \\
\hline & $(0.19)$ & & & $(0.78)$ & $(0.25)$ \\
\hline variance & 35.40 & 27.10 & 45.36 & 15.79 & 52.66 \\
\hline Loglik & -2067.29 & \multicolumn{2}{|c|}{-2060.70} & \multicolumn{2}{|c|}{-2024.83} \\
\hline $\mathrm{P}_{11}$ & & $1.00^{* * *}$ & & $1.00^{* * *}$ & \\
\hline $\mathrm{P}_{22}$ & & & $0.94^{* * *}$ & & $0.98^{* * *}$ \\
\hline \multicolumn{6}{|c|}{ Expected duration of regime } \\
\hline Regime1 & & 1309.49 & & 266.96 & \\
\hline
\end{tabular}




\begin{tabular}{lll}
\hline Regime2 & 16.62 & 64.00
\end{tabular}

Table 4-4. Ccommunication \& internet stock

\begin{tabular}{|c|c|c|c|c|c|}
\hline & \multirow[t]{2}{*}{ Regression } & \multicolumn{2}{|c|}{ MSM-TV } & \multicolumn{2}{|c|}{ MSM-TV-MB } \\
\hline & & Regime1 & Regime2 & Regime1 & Regime2 \\
\hline \multirow[t]{2}{*}{ intercept } & $-1.83^{* * *}$ & $-2.50^{* * *}$ & 5.88 & $0.93^{*}$ & $-3.35^{* * *}$ \\
\hline & $(0.47)$ & $(0.42)$ & $(5.07)$ & $(0.46)$ & $(1.06)$ \\
\hline \multirow[t]{2}{*}{$\mathrm{TV}$} & $0.29^{* * *}$ & 0.19 & $0.76^{*}$ & $0.39^{* * *}$ & $0.27^{* * *}$ \\
\hline & $(0.04)$ & $(0.03)$ & $(0.37)$ & $(0.04)$ & $(0.08)$ \\
\hline \multirow[t]{2}{*}{ MB } & $-0.43^{* *}$ & & & $-2.39^{* * *}$ & $0.05^{* * *}$ \\
\hline & $(0.19)$ & & & $(0.30)$ & $(0.42)$ \\
\hline variance & 59.51 & 44.75 & 86.80 & 14.43 & 108.64 \\
\hline Loglik & -2234.96 & \multicolumn{2}{|c|}{-2205.49} & \multicolumn{2}{|c|}{-2155.37} \\
\hline $\mathrm{P}_{11}$ & & $0.96^{* * *}$ & & $0.87^{* * *}$ & \\
\hline $\mathrm{P}_{22}$ & & & 0.24 & & $0.83^{* * *}$ \\
\hline \multicolumn{6}{|c|}{ Expected duration of regime } \\
\hline Regime1 & & 23.32 & & 7.42 & \\
\hline Regime2 & & & 1.32 & & 5.77 \\
\hline
\end{tabular}

Table 4-5. Electronic parts \& components stock

\begin{tabular}{|c|c|c|c|c|c|}
\hline & \multirow[t]{2}{*}{ Regression } & \multicolumn{2}{|c|}{ MSM-TV } & \multicolumn{2}{|c|}{ MSM-TV-MB } \\
\hline & & Regime1 & Regime2 & Regime1 & Regime2 \\
\hline \multirow[t]{2}{*}{ intercept } & -0.59 & $-0.72^{* *}$ & 0.23 & -0.84 & -0.14 \\
\hline & $(0.63)$ & $(0.33)$ & $(0.67)$ & $(0.63)$ & $(0.78)$ \\
\hline \multirow[t]{2}{*}{$\mathrm{TV}$} & $0.41^{* * *}$ & $0.68^{* * *}$ & 0.04 & 1.48 & $0.55^{* * *}$ \\
\hline & $(0.09)$ & $(0.09)$ & $(0.17)$ & (Inf) & $(0.11)$ \\
\hline \multirow[t]{2}{*}{ MB } & -0.03 & & & -0.42 & $-0.85^{* * *}$ \\
\hline & $(0.20)$ & & & $(0.26)$ & $(0.23)$ \\
\hline variance & 25.00 & 19.28 & 29.24 & 19.19 & 29.30 \\
\hline Loglik & -1954.86 & \multicolumn{2}{|c|}{-1942.51} & \multicolumn{2}{|c|}{-1942.54} \\
\hline $\mathrm{P}_{11}$ & & \multicolumn{2}{|l|}{0.91} & \multicolumn{2}{|l|}{$0.91^{* *}$} \\
\hline $\mathrm{P}_{22}$ & & & 0.78 & & $0.85^{* * *}$ \\
\hline \multicolumn{6}{|c|}{ Expected duration of regime } \\
\hline Regime1 & & 11.52 & & 11.05 & \\
\hline
\end{tabular}




\begin{tabular}{lll} 
Regime2 & 4.57 & 6.58 \\
\hline
\end{tabular}

Table 4-6. Electronic product distribution stock

\begin{tabular}{|c|c|c|c|c|c|}
\hline & \multirow[t]{2}{*}{ Regression } & \multirow{2}{*}{$\begin{array}{l}\text { MSM-TV } \\
\text { Regime1 }\end{array}$} & \multicolumn{3}{|c|}{ MSM-TV-MB } \\
\hline & & & Regime2 & Regime1 & Regime2 \\
\hline \multirow[t]{2}{*}{ intercept } & $-1.21^{*}$ & $-0.92^{* * *}$ & $-5.89^{* * *}$ & -0.37 & $-6.62^{* * *}$ \\
\hline & $(0.64)$ & $(0.31)$ & $(1.48)$ & $(0.56)$ & $(1.94)$ \\
\hline \multirow[t]{2}{*}{$\mathrm{TV}$} & $0.32^{* * *}$ & $0.51^{* * *}$ & $0.71^{* * *}$ & $0.40^{* * *}$ & $0.66^{* * *}$ \\
\hline & $(0.06)$ & $(0.12)$ & $(0.15)$ & $(0.08)$ & $(0.15)$ \\
\hline \multirow[t]{2}{*}{ MB } & 0.03 & & & -0.10 & $0.47^{* * *}$ \\
\hline & $(0.24)$ & & & $(0.23)$ & $(0.56)$ \\
\hline variance & 32.45 & 14.87 & 65.43 & 11.89 & 72.29 \\
\hline Loglik & -2039.13 & \multicolumn{2}{|c|}{-1944.71} & \multicolumn{2}{|c|}{-1944.08} \\
\hline $\mathrm{P}_{11}$ & & $1.00^{* * *}$ & & $0.97^{* *}$ & \\
\hline $\mathrm{P}_{22}$ & & & $0.99^{* * *}$ & & 0.87 \\
\hline \multicolumn{6}{|c|}{ Expected duration of regime } \\
\hline Regime1 & & 6762.56 & & 30.62 & \\
\hline Regime2 & & & 95.34 & & 7.74 \\
\hline
\end{tabular}

Table 4-7. Information service stock

\begin{tabular}{|c|c|c|c|c|c|}
\hline & \multirow[t]{2}{*}{ Regression } & \multicolumn{2}{|c|}{ MSM-TV } & \multicolumn{2}{|c|}{ MSM-TV-MB } \\
\hline & & Regime1 & Regime2 & Regime1 & Regime2 \\
\hline \multirow[t]{2}{*}{ intercept } & $-1.13^{* * *}$ & $-0.75^{* *}$ & $-2.15^{* * *}$ & $-1.15^{* *}$ & -0.39 \\
\hline & $(0.37)$ & $(0.31)$ & $(0.59)$ & $(0.48)$ & $(1.59)$ \\
\hline \multirow[t]{2}{*}{ TV } & $0.32^{* * *}$ & $0.33^{* * *}$ & $0.33^{* * *}$ & $0.25^{* * *}$ & $1.09^{* * *}$ \\
\hline & $(0.04)$ & $(0.06)$ & $(0.06)$ & $(0.04)$ & $(0.15)$ \\
\hline \multirow[t]{2}{*}{ MB } & -0.28 & & & $-0.71^{* * *}$ & -0.02 \\
\hline & $(0.20)$ & & & $(0.25)$ & $(0.20)$ \\
\hline variance & 43.41 & 11.70 & 66.83 & 31.90 & 48.90 \\
\hline Loglik & -2133.09 & \multicolumn{2}{|c|}{-2094.10} & \multicolumn{2}{|c|}{-2103.59} \\
\hline $\mathrm{P}_{11}$ & & \multicolumn{2}{|l|}{$0.86^{*}$} & \multicolumn{2}{|l|}{$0.82^{* *}$} \\
\hline $\mathrm{P}_{22}$ & & \multicolumn{2}{|r|}{$0.89^{* * *}$} & & 0.07 \\
\hline Expected & & & & & \\
\hline
\end{tabular}


Regime1

Regime2
7.10

9.09
5.61

1.08

Table 4-8. Other electronic industries stock

\begin{tabular}{|c|c|c|c|c|c|}
\hline & \multirow[t]{2}{*}{ Regression } & \multicolumn{2}{|l|}{ MSM-TV } & \multicolumn{2}{|c|}{ MSM-TV-MB } \\
\hline & & Regime1 & Regime2 & Regime1 & Regime2 \\
\hline \multirow[t]{2}{*}{ intercept } & -0.13 & $-1.32^{* * *}$ & $-2.25^{* * *}$ & -0.44 & $-1.10^{*}$ \\
\hline & $(0.34)$ & $(0.26)$ & $(0.61)$ & $(0.56)$ & $(0.67)$ \\
\hline \multirow[t]{2}{*}{ TV } & $0.55^{* * *}$ & $0.59^{* * *}$ & $0.37^{* * *}$ & $0.62^{* * *}$ & $0.61^{* * *}$ \\
\hline & $(0.06)$ & $(0.09)$ & $(0.08)$ & $(0.12)$ & $(0.10)$ \\
\hline \multirow[t]{2}{*}{ MB } & $-1.71^{* * *}$ & & & $-0.95^{*}$ & $-1.70^{* * *}$ \\
\hline & $(0.31)$ & & & $(0.57)$ & $(0.46)$ \\
\hline variance & 26.49 & 9.77 & 48.80 & 8.13 & 46.24 \\
\hline Loglik & -1973.56 & -1915.79 & & -1897.03 & \\
\hline $\mathrm{P}_{11}$ & & $0.99^{* *}$ & & $0.96^{* *}$ & \\
\hline $\mathrm{P}_{22}$ & & & $1.00^{* *}$ & & $0.96^{* *}$ \\
\hline \multicolumn{6}{|c|}{ Expected duration of regime } \\
\hline Regime1 & & 70.34 & & 26.60 & \\
\hline Regime2 & & & 393.66 & & 22.57 \\
\hline
\end{tabular}

Note: The asterisks refer to the level of significance, ${ }^{*} 10 \%,{ }^{* *} 5 \%,{ }^{* * *} 1 \%$. Loglik is the log-likelihood.

The numbers indicated in parenthesis are standard error.

The MSM-TV model has 6 stocks perform significant two regimes, the results are better than the sub-electron industries indexes. Persistence of stocks expected duration are high, the probabilities are all above 0.84 . For example, the regime one expected duration of semiconductor stock is 8.74 weeks, regime two is 6.16 weeks.

The MSM-TV-MB model has 4 stocks perform significant two regimes. The results are worse than the MSM-TV model. Persistence of stocks expected duration are still high, the probabilities are all above 0.82 . The regime one expected duration of semiconductor stock is 9.23 weeks, regime two is 5.64 weeks. The expected durations have minor changed after adding MB in the MSM.

The log likelihood value for the MSM-TV model and MSM-TV-MB model is well above the regression model for these stocks. The variance and coefficient are significant different across regimes. However, the comparisons results between the MSM-TV model and MSM-TV-MB model are mixed. For the 8 stocks sample, here we have 4 stocks which their log likelihood value are similar, 3 stocks the MSM-TV-MB model higher than MSM-TV model, 1 stock the MSM-TV-MB model lower than MSM-TV model. It may come to the conclusion that the MB factor does affect the probabilities of the expected duration of regime. But the influences are not the same across different stocks. Maybe the MB factor is not an affected factor for stock returns.

This paper performs sensitivity analysts to verify whether the stock returns are better characterized by MSM-TV or MSM-TV-MB. For the purpose of capturing the quality of regime classification, this paper calculate the regime classification measurement (RCM) developed by Ang and Bekaert (2002a, b). The measure is based on the idea that the MSM should classify regimes sharply, so that the ex-post regime probabilities $p_{t}$ are close to zero. Weak regime inference implied that the MSM cannot successfully distinguish between regimes from the behavior of the data and may indicate misspecification. The RCM for an MSM with K regimes are defined as follows: 


$$
R C M \quad(K)=100 \quad K^{2} \times \frac{1}{T} \sum_{t=1}^{T}\left(\prod_{i=1}^{K} p_{i, t}\right)
$$

where $\mathrm{T}$ is the sample size. The RCM takes a value between zero and one hundred. Good regime classification is associated with low RCM values. A model which distinguishes poorly between regimes will have an RCM value close to one hundred. Table 5 presents the MSM-TV RCM and MSM-TV-MB RCM for stocks. The RCM statistics for the stocks are all below 50, communication \& internet stock are only 18.89, implying a satisfactory regime classification. The RCM statistics show that the MSM-TV and MSM-TV-MB have similar performance.

Table 5. RCM statistics

\begin{tabular}{llll}
\hline Stock & MSM-TV & & MSM-TV-MB \\
\hline semiconductor & 35.64 & $>$ & 35.01 \\
computer \& peripheral equipment & 21.14 & $>$ & 21.91 \\
optoelectronic & 30.11 & $<$ & 42.13 \\
communication \& internet & 18.89 & $<$ & 26.25 \\
electronic parts \& components & 23.04 & $>$ & 20.91 \\
electronic product distribution & 21.44 & $<$ & 48.60 \\
information service & 39.14 & $>$ & 24.00 \\
other electronic industries & 28.40 & & \\
\hline
\end{tabular}

The use of MSM raises an important question: How many regimes are more appropriate to capture the behavior of stocks? Some authors suggested a two-regime MSM, while some recommended a three-regime MSM. This paper selected the optimal model by minimum Akaike information criteria (AIC) and tested the two-regime MSM and three-regime MSM separately. It is worth noting that most of the three-regime MSM parameters are not significant. The results of this paper suggest a two-regime Markov switching model to investigate the relationship between stock return and trading volume.

This sub-section uses the MSM to evaluate the individual stock, it is found that there are two regimes and the regimes are highly persistent just the same as previous sections. Variations of volatilities are largely across different stocks. The results have the similar perform as the sub-section 3.3 and 3.4 , which on behalf of the sub-industry, industry and market level.

\section{Conclusions}

One astonishing finding of stock market is that trading volume provides an important link for future stock returns. This phenomenon shows that the affection of trading volume on stock price is more complex than EMH suggested. By the efforts of previous studies, financial academics try to draw the picture of it. However, it still left some inconclusive evidences.

This paper first uses the regression model to examine the relationship between stock returns and trading volume. It is found that the $R^{2}$ between market return and trading volume is $4.52 \%$. Automobile industry earns the higher relationship which is only $9.85 \%$. The relationship between stock returns and trading volume is not a one-one function.

The choice of a regime-switching model stems from the failure of the traditional regression model to detect relationship between trading volume and stock returns. This paper adopts the idea of Engle and Hamilton (1990) by loosens the assumption of single regime. In the MSM, conditional distribution of the mean depends on the value of a non-observable regime variable. This paper applies it to the market and every industry lists in TWSE. The results show that there is always a second regime that is difficult to explain theoretically. This is consistent with earlier studies indicating that are complex influences in stock returns. The fact that the MSM are able to capture the relationship well is in line with many empirical works. By comparing among industries and the market, it is found that industry factor is important. The volatilities of different industries served a wild rang variation.

In order to make a more robust test, this paper further evaluates the sub-electron industry and finally the 
individual stocks. The sub-industry and the individual stock all perform the similar results as the previous test. This paper further tests the glamour (value) stock effect by using the MSM. It is found that the factor does affect the probabilities of the expected duration periods. However, only few of the volatilities are significant. Maybe this is not an affected factor for stock returns.

The MSM has clearly revealed that there are two regimes. Not clear are possible reasons for the instability. One possible explanation would be that people are not always rational, their financial decision making are influenced by behavioral biases. If people change their beliefs or preferences, then the regime switches. Like Barberies et al. (1998) said that investor sentiment is a regime-switching process. These findings provide evidences to convince that market participants regard the important of information as time-varying.

How does trading activity vary from stock to stock, and why? It is up to further research and beyond the present promising indications. This leads to the conclusion that, although the MSM captures most of the structural instability in the equations, there is still some source of variation left to be discovered.

\section{References}

Amihud, Y. (2002). Illiquidity and stock returns: cross-section and time series effects. Journal of Financial Markets, 5, 31-56. http://dx.doi.org/10.1016/S1386-4181(01)00024-6

Ang, A., \& Bekaert, G. (2002a). International asset allocation with regime shifts. Review of Financial Studies, 15, 1137-1187. http://dx.doi.org/10.1093/rfs/15.4.1137

Ang, A., \& Bekaert, G. (2002b). Regime switches in interest rates. Journal of Business \& Economic Statistics, 20, 163-182. http://dx.doi.org/10.3386/w6508

Baker, M., \& Wurgler, J. (2006). Investor sentiment and the cross-section of stock returns. Journal of Finance, 61, 1645-1680. http://dx.doi.org/10.1111/j.1540-6261.2006.00885.x

Barberis, N., Shleifer, A., \& Vishny, R. (1998). A model of investor sentiment. Journal of Financial Economics, 49, 307-343. http://dx.doi.org/10.1016/S0304-405X(98)00027-0

Blume L., Easley D., \& O'Hara, M. (1994). Market statistics and technical analysis: the role of volume. Journal of Finance, 49, 153-181. http://dx.doi.org/10.1111/j.1540-6261.1994.tb04424.x

Copeland, T. E. (1976). A model of asset trading under the assumption of sequential information arrival. Journal of Finance, 31, 1149-1168. http://dx.doi.org/10.1111/j.1540-6261.1976.tb01966.x

Conrad, J. S., Hameed A., \& Niden, C. (1994). Volume and autocovariance in short-horizon individual security returns. Journal of Finance, 49, 1305-1329. http://dx.doi.org/10.1111/j.1540-6261.1994.tb02455.x

Daniel, K. D., Hirshleifer, D., \& Subrahmanyam, A. (1998). Investor psychology and security market under- and overreactions. Journal of Finance, 53, 1839-1886. http://dx.doi.org/10.1111/0022-1082.00077

Ding, D. K., MeInish, T. H., \& Wongchoti, U. (2008). Behavioral explanations of trading volume and short-horizon price patterns: An investigation of seven Asia-Pacific markets. Pacific-Basin Finance Journal, 16, 183-203. http://dx.doi.org/10.1016/j.pacfin.2007.01.002

Engel, C., \& Hamilton, J. D. (1990). Long swings in the dollar: are they in the data and do markets know it? American Economic Review, 80, 689-713.

Epps, T. W. (1975). Security price changes and transaction volumes: some additional evidence. American Economic Review, 65, 586-597.

Fama, E. F. (1991). Efficient capital markets II. Journal of Finance, 46, 1575-1617. http://dx.doi.org/10.1111/j.1540-6261.1991.tb04636.x

Gervais, S., Kaniel, R., \& Mingelgrin, D. H. (2001). The high-volume return premium. Journal of Finance, 56, 877-919. http://dx.doi.org/10.1111/0022-1082.00349

Gurgil, P., \& Syrek, R. (2013). Testing of dependencies between stock returns and trading volume by high frequency data. Managing Global Transitions, 11, 353-373.

Hamilton, J. D. (1989). A new approach to the economic analysis of nonstationary time series and business cycle. Econometrica, 57, 357-384.

Hamilton, J. D. (1994). Time Series Analysis. Princeton: Princeton University Press.

Hong, H., \& Stein, J. C. (1999). A unified theory of underreaction, momentum trading, and overreaction in asset markets. Journal of Finance, 54, 2143-2184. http://dx.doi.org/10.1111/0022-1082.00184 
Jennings, R. H., Starks, L. T., \& Fellingham, J. C. (1981). An equilibrium model of asset trading with sequential information arrival. Journal of Finance, 36, 143-161. http://dx.doi.org/10.1111/j.1540-6261.1981.tb03540.x

Lee, C., \& Swaminathan, B. (2000). Price momentum and trading volume. Journal of Finance, 55, 2017-2069. http://dx.doi.org/10.1111/0022-1082.00280

Lou, X., \& Shu, T. (2014). Price impact or trading volume: why is the Amihud (2002) illiquidity measure price? Working paper, 1-52.

Odean, T. (1998). Are investors reluctant to realize their losses? Journal of Finance, 53, 1775-1798. http://dx.doi.org/10.1111/0022-1082.00072

Shefrin, H., \& Statman, M. (1985). The disposition to sell winners too early and ride losers too long: Theory and evidence. Journal of Finance, 40, 777-790. http://dx.doi.org/10.1111/j.1540-6261.1985.tb05002.x

\section{Copyrights}

Copyright for this article is retained by the author(s), with first publication rights granted to the journal.

This is an open-access article distributed under the terms and conditions of the Creative Commons Attribution license (http://creativecommons.org/licenses/by/3.0/). 